\title{
A TECNOLOGIA COMO FATOR DETERMINANTE NAS COMPOSIÇÕES DE LUCIANO BERIO NAS DÉCADAS DE 1950 E 1960
}

\author{
Kelly Nogueira Marques \\ Universidade Estadual Paulista - UNESP, Doutorado em Música, Instituto de Artes IA, São Paulo, SP. E-mail: \\ kellymarkes@hotmail.com
}

\begin{abstract}
RESUMO
Este trabalho baseia-se na minha Dissertação de Mestrado que desenvolvi acerca da influência da tecnologia nas obras do compositor Luciano Berio. Assim este artigo tem o objetivo de analisar como a invenção de tecnologias no âmbito da música impulsionou a transformação da linguagem musical. De fato, toda invenção tecnológica no campo da música reflete-se em mudanças na concepção musical. A integração das novas realidades na música não se limitou à reflexão de influências através dos processos tradicionais, mas aproveitou de modo extraordinário os desenvolvimentos tecnológicos e as descobertas científicas, tanto a nível acústico, psico-acústico, como dos novos instrumentos e possibilidades da técnica.
\end{abstract}

Palavras-chave: Tecnologia, Composição, Análise, Luciano Berio, Manipulação Sonora.

\section{THE TECHNOLOGY AS A DETERMINING FACTOR IN THE COMPOSITIONS OF LUCIANO BERIO IN THE 1950S AND 1960S.}

\begin{abstract}
This work is based on my Master's thesis I developed about the influence of technology in the works of the composer Luciano Berio. So this article aims to analyze how the invention of technologies in music propelled the transformation of musical language. In fact, every technological invention in the field of music is reflected in changes in the musical design. The integration of the new realities in music was not limited to the reflection influences through traditional processes, but took an extraordinary way of technological developments and scientific discoveries, both the noise level, psycho-acoustic, as the new tools and technique possibilities.

Keywords: Technology, Composition, Analysis, Luciano Berio, handling Sonora.
\end{abstract}




\section{INTRODUÇÃO}

É a década de 1950 que temos o maior desenvolvimento acerca dos estúdios, o que nos conduz portanto ao objeto de estudo deste trabalho que assim está centrado nos gestos eletrônicos, nos espectros, na passagem de notas para som e na voz na qualidade de instrumento musical e para isso, foram escolhidas obras: Thema - Omaggio a Joyce (1958) e Laborintus 2 (1965) do compositor Luciano Berio. Veremos portanto que além de explorar o contexto funcional das máquinas (tecnologia da época), a criação, meios e ideias estéticas e a forma de experimentação, também a composição percorreu um caminho de exploração de potencialidades expressivas e estéticas dentro da revolução que foi o desenvolvimento tecnológico.

Pierre Boulezdes descreveu, em 1955, a situação com a qual todos os compositores alemães de música eletrônica se confrontavam:

[...] raramente se assistiu, na história da música, a uma evolução mais radical, considerando-se que o músico encontra-se diante de uma situação inusitada: a criação do próprio som. E não pela escolha do material sonoro com vistas a um efeito decorativo, ou para ressaltar algo - isso seria banal, seria transpor para um outro domínio os problemas de orquestração ou de instrumentação que servem de base atualmente; mas trata-se da escolha do material devido às qualidades de estrutura intrínseca que ele comporta [...] (Boulez, 1995, p. 188).

O objetivo é evidenciar que a tecnologia foi um fator determinante nas composições desta época, nomeadamente pela presença dos elementos novos: novos sons, novos timbres, novos ritmos, novas estruturas musicais, novos materiais e novos interesses.

\section{METODOLOGIA}

Para atender aos objetivos propostos da pesquisa, o método adotado foi o analíticodescritivo, o qual contemplará o levantamento bibliográfico e a coleta de dados baseada em fontes secundárias.

O levantamento bibliográfico, tipo de pesquisa de caráter exploratório, foi realizado com a intenção de se obter conhecimentos a partir de informações já publicadas.

O trabalho foi constituído por duas partes: a 1a descrever brevemente o contexto histórico-musical no qual se enquadram as obras, enquanto na 2a representará a parte essencial deste trabalho e consistirá numa análise do conteúdo das obras.

Quanto ao método de análise de dados, realizou-se um levantamento de informações necessárias à pesquisa através da leitura e análise de documentos, tais como consultas à correspondências, manuscritos e livros referentes as obras e vida do compositor Luciano Berio. Além do contato e funcionalidade dos instrumentos eletrônicos que fazem parte da produção musical, como: geradores de som (osciladores, gerador de ruído branco), modificadores de som (filtro passa banda variável, analisador de espectro), equipamento de gravação e reprodução (microfones, mixer console, tape gravadores).

Há também alguns materiais originais do estúdio de Fonologia (fitas, correspondência do compositor, etc), na RAI (Radiotelevisione Italiana) em Milão no "Archivio di Estúdio da Fonologia", que também foi visitado para recolher dados.

\section{RESULTADOS}

A partir das obras selecionadas para alcançar o objetivo proposto, brevemente descrevo os resultados de análise de cada obra.

Thema - Omaggio a Joyce que é uma obra eletroacústica composta em 1958, para voz e fita magnética, em que uma leitura da primeira parte do Capítulo XI do Ulysses feita pela cantora 
Cathy Berberian, é gravada e depois trabalhada, utilizando as técnicas disponíveis no Estúdio de Milão para criação de efeitos sonoros, tais como: eco, distorção, sobreposição, alteração de velocidade e timbre entre outros. A duração total da obra gravada em estéreo é de cerca de $8^{\prime} 30^{\prime \prime}$. Sendo a manipulação eletroacústica de Berio cerca de 6'31", e são precedidos por 1'59" de leitura por Cathy Berberian. Thema - Omaggio a Joyce, onde todos os sons, mesmo os que sugerem ser completamente eletrônicos a uma primeira escuta, foram derivados da gravação da voz de Cathy Berberian.

Sendo Thema uma obra eletroacústica ela é, por definição, dependente das técnicas de estúdio na sua composição. No entanto, o que busca se compreender aqui é de que modo essas técnicas foram determinantes na composição da obra em si mesma, para além da sua natural dependência do estúdio e das possibilidades técnicas da época.

A possibilidade de captação, manipulação e gravação dos sons proporcionaram ao compositor gravar e reproduzir os sons actuais, manipular altura e ritmo pela alteração da velocidade de sons gravados, arranjar, separar e sobrepor esses sons. Desde então, o som podia ser dilatado, contraído, modificado timbricamente, sobreposto, deslocado e reprocessado. Várias destas possibilidades de manipulação e transformação do som encontram-se presentes na obra de Berio Thema - Omaggio a Joyce (1958).

Em Laborintus 2 (1965), obra para voz cantada, narrador, ensemble instrumental e fita magnética, (especificamente, fita magnética difundida em 4 alto-falantes posicionados em palco, narrador, três cantoras, e um coro de oito vozes de atores, enquanto as forças instrumentais compõem quinze instrumentos incluindo percussão) com a duração de 33 minutos, foi composta entre 1963 e 1965. A obra é baseada no poema Laborintus de Edoardo Sanguineti, em que alguns temas de Vita Dante Nova, Convivio e Divina Commedia são usados. Combina estes textos com trechos da Bíblia e com textos de Ezra Pound e Thomas Stearns Eliot.

Laborintus 2 contém uma sequência de situações e atitudes dramáticas que são estabelecidas pela palavra falada, e depois estendidas e elaboradas pela música. A obra é composta na parte central por uma seção de carácter jazzístico que desemboca numa seção de sons eletrônicos. A fita magnética Laborintus 2 foi feita no estúdio de fonologia de Milão e na Universidade de Columbia, em Nova York, em 1963, e as características da parte eletrônica são desenvolvidas a partir da parte instrumental da obra. Em 1965, Berio já tinha realizado algumas experiências usando a eletrônica, entre elas: Thema - Omaggio a Joyce, Différences, Visage. E foram essas experiências que o encorajaram a compor em 1963, a secção eletroacústica de Laborintus 2.

As obras de Berio são definidas por vezes por estruturas de interação, combinam sons naturais e recursos eletrônicos, campos de texto, gestos, voz e gestos dramatúrgicos, gêneros musicais e ações teatrais, ou seja, incluem o desenvolvimento de uma variedade de recursos. Em Laborintus 2, há desenvolvimento em termos de sistemas de geração de som, manipulação das técnicas de distribuição, vocal e instrumental eletrônico de zonas de som. Em momentos, a acumulação de eventos sonoros simultâneos tornam-se particularmente densa e pode parecer caótica, como o próprio Berio diz: "[...] São as ondas de densidade na polifonia que dão forma a tudo aparentemente caótico [...]"1 (Trad. nossa), Em entrevista realizada por Rossana Dalmonte, Berio diz que, "[...] Laborintus 2, é um trabalho baseado essencialmente na continuidade entre discurso instrumental e vocal [...]"(Dalmonte, 1981, p.27.)

Nesta obra a fita magnética: sons eletrônicos estão em uso com mais espaço no decorrer da obra, sendo estes sons eletrônicos com variados timbres, durações e efeitos, a orquestra quase não interage neste momento com mais espaco ao eletrônico. Os sons eletrônicos voltam a interagir à parte instrumental gradativamente, mas ainda sim com alguns cortes de

1 STOIANOVA, Ivanka.“Luciano Berio - Chemins en musique”, in: La Revue Musicale número triplo 375-6-7. Paris: Éditions Richard-Masse. 1985. Original: Ce sont des ondes de densité dans la polyphonie de comportement qui façonnent tous apparemment chaotique. 
silêncio. E mais uma vez constata-se como o meio eletrônico bem como as técnicas de estúdio, foram relevantes em muitas obras de Berio e contribuíram para o desenvolvimento e aprimoramento do uso da tecnologia nas composições.

\section{DISCUSSÃO}

Sendo as obras selecionadas todas com componente eletrônica, ou seja, sendo por definição, dependente da tecnologia por meio das técnicas de estúdio na sua composição. Vemos como a tecnologia em questão foi determinante nestas obras. Neste sentido pode-se constatar que o compositor que tenha tido conhecimento e acesso aos estúdios de música eletrônica e eletroacústica sabe bem a infinidade de possibilidades sonoras que podem proporcionar, as novas técnicas e conhecimentos, assim como a forma como estes podem influenciar a maneira de compor. $O$ fazer música sob a influência da tecnologia abre novos horizontes aos compositores.

As questões que levanto neste momento são: Até que ponto a tecnologia pode ser um fator determinante numa composição ? Será possível se obter uma sonoridade antes conseguida apenas por meios eletrônicos agora por instrumentos reais?

\section{CONCLUSÃO}

Vivemos numa época onde a tecnologia se dissemina com rapidez, onde o novo, o moderno e o avanço tecnológico estão sempre em evidência, causando interesse seja para experimentar apenas ou explorarem capacidades com intuitos artísticos ou outros. Este fenómeno já ocorria nas décadas de 1950 e 1960 ao qual se concentra esta pesquisa, influenciando de forma inequívoca no fazer música desta época.

Da experiência de observar estas obras, considera-se que Berio, expandiu as possibilidades de composição por meio da interação entre as suas ideias composicionais e os recursos tecnológicos, de forma muitas vezes sutil. Foram observadas, nas seções e nos elementos constituintes das obras: a influência da tecnologia, o uso do instrumento musical, o jogo contrapontístico entre ideias composicionais no sentido da música instrumental e as derivadas do estúdio assim como a integração de estilos diversos. Além da própria organização, a conexão e a interação dos elementos que compõem a obra no caso de Laborintus 2 (1965), mostram a criação de um todo coerente e equilibrado entre diversidade de elementos, técnicas e influências.

\section{REFERÊNCIAS}

BERIO, L. Remembering the Future. Cambridge, Massachusetts: Harvard University, 2006. Laborintus II. Milano: Universal, 1976.

BOULEZ, Pierre. Apontamentos de aprendiz. Editora Perspectiva, São Paulo. 1995.

CASTELLANI, Felipe Merker. Uma abordagem sobre a noção de gesto musical nas poéticas de Luciano Berio e Brian Ferneyhough. 189 f. Dissertação de Mestrado - Instituto de Artes, Universidade de Campinas, 2010.

DALMONTE, Rossana. S. d. Luciano Berio. Entrevista sobre a música contemporânea. São Paulo: Civilização Brasileira, 1981.

MENEZES, Florivaldo Filho. Música maximalista: ensaios sobre a música radical e especulativa. São Paulo: UNESP, 2006.

. Luciano Berio et la phonologie - Une approche jakobsonienne de son oeuvre. Frankfurt:

Publications Universitaires Européennes, Peter Lang (ed.), 1993. 
. Atualidade estética da música eletroacústica. São Paulo: Ed. Unesp, 1999.

. Música eletroacústica: história e estética.São Paulo: Ed. Unesp, 1996.

STOIANOVA, Ivanka. Luciano Berio - Chemins en musique. La Revue Musicale, Paris, Éditions Richard-Masse, triplo, 375-6-7, 1985.

VARÈSE, E. Écrits. Textes réunis et présentés par Louise Hirbour. Paris: C. Bourgeois, 1983. 